Journal of Clinical Investigation

Vol. 41, No. 6, 1962

\title{
THE CATECHOLAMINES IN THE PULMONARY ARTERIAL PRESSOR RESPONSE TO ACUTE HYPOXIA *
}

\author{
By ROBERTA M. GOLDRING, GERARD M. TURINO, GERALD COHEN, A. GREGORY \\ JAMESON, BERL G. BASS AND ALFRED P. FISHMAN
}

\author{
(From the Departments of Medicine and Biochemistry, Columbia University, College of Physi- \\ cians and Surgeons, and the Cardiorespiratory Laboratory of the Presbyterian \\ Hospital, New York, N. Y.)
}

(Submitted for publication December 1, 1961; accepted February 1, 1962)

A moderate reduction in the oxygen content of inspired air elicits an increase in the pulmonary arterial pressure in animals and man (1-5). It has been suggested that the catecholamines may be involved in this pressor response $(6,7)$. However, it is uncertain if this hypothesis applies to the effects of tolerable levels of hypoxia in man, since the experimental evidence for enhanced adrenal activity derives exclusively from observations made during severe hypoxia and asphyxia in animals (8-17).

The present study attempted to assess the role of the catecholamines in effecting the pulmonary arterial pressor response to acute hypoxia in man. To supplement these observations on man, experiments were performed on reserpinized dogs to determine whether the pulmonary arterial pressor response to acute hypoxia persists after depleting the pulmonary vascular nerve endings of norepinephrine.

\section{MATERIALS AND METHODS}

\section{Subjects}

Twenty-two subjects were studied in the unanesthetized, postabsorptive, "basal" state. All of these subjects were either entirely normal or else had small, circumscribed pulmonary lesions. Their ages ranged from 14 to 54 years.

Three other subjects were studied during the course of thoracotomy. Two had discrete pulmonary neoplasms; the other had a discrete, small mediastinal tumor. Their ages were 22,24 , and 59 years, respectively.

* Presented, in part, at the Forty-fourth Annual Meeting of the American Physiological Society, Chicago, Ill., April 11-15, 1960. Supported, in part, by Research Grants H-2299 (Medicine) and H-1045 (Biochemistry) from the National Institutes of Health, U. S. Public Health Service, with additional support from the American Heart Association and the New York Heart Association.
Five dogs were used for the part of the study designed to deplete pulmonary vascular nerve endings of norepinephrine.

\section{Methods}

For convenience in presentation, the study has been subdivided into four parts.

Part I. Preliminary observations were made on 9 subjects. These consisted of a comparison of the concentrations of epinephrine and norepinephrine in systemic arterial blood prior to and during 15 minutes of breathing 11 per cent oxygen in nitrogen. The results of these studies are included in Table I (Subjects TM to DG).

Part II. More extensive observations were made on 13 other subjects. The right heart was catheterized in each of these subjects with a double-lumen catheter. The brachial artery was cannulated with a Cournand needle. Open circuits were used to administer specific inspired mixtures and to collect expired gas. Each study consisted of four consecutive periods: 1) control, 2) acute hypoxia, 3) infusion of norepinephrine, and 4) acute hypoxia during the infusion of norepinephrine. Between periods, the subject was disconnected from the open circuit for 15 to 30 minutes of relaxation and ambient air breathing.

Control, ambient air (period 1): Ten to 15 minutes after the completion of right heart catheterization and brachial arterial cannulation, a period of ambient air breathing was begun; the open-circuit system consisted of a mouthpiece, a three-way, low dead space valve, and a Tissot gasometer. After 15 minutes of breathing ambient air, the expired air was collected for 2 minutes. During the middle minute of the gas collection, samples of mixed venous and peripheral arterial blood were withdrawn simultaneously for the determination of the gaseous composition, $\mathrm{pH}$, and concentration of catecholamines.

Acute hypoxia (period 2): During this period, a mixture of 11 per cent oxygen in nitrogen was substituted for ambient air. This inspired mixture was breathed for 16 minutes. During the last 2 minutes, expired gas and blood samples were collected as in the preceding period.

Infusion of norepinephrine (period 3): The third period involved the intravenous administration of norepinephrine in saline. The initial rate of infusion was 4 to $6 \mu \mathrm{g}$ per minute; it was increased every 3 to 5 minutes until the pulmonary arterial blood pressure reached the 
level which had occurred spontaneously during acute hypoxia. The final rate of infusion was different for each subject; it ranged from 12 to $67 \mu \mathrm{g}$ per minute. This rate of infusion was continued for 10 minutes to achieve a constant blood level of norepinephrine (18). During the final 2 minutes of the infusion, blood and gas samples were withdrawn as during the previous periods.

Acute hypoxia during the infusion of norepinephrine (period 4): Between the third and fourth periods, the infusion of norepinephrine was continued. In 5 of the subjects, the rate of infusion was unchanged (20 to $67 \mu \mathrm{g}$ per minute); in the other 8 , the rate of infusion was gradually reduced until the pulmonary arterial pressure returned to the preinfusion level (final rates of infusion from 4 to $20 \mu \mathrm{g}$ per minute). In each instance, the infusion rate was kept constant for 10 minutes before the subject began to breathe the hypoxic inspired mixture (as in period 2). The duration of the hypoxic period, as well as the times of sampling both expired gas and blood, was the same as in the previous periods.

Blood pressures were recorded every 4 minutes during the first two periods and continuously during the last two periods. The recording system consisted of Statham strain gauges as pressure transducers and an oscilloscopic recording apparatus (Electronics for Medicine). The usual criteria were applied for adequacy of the pulmonary wedge pressure (19). Pulmonary vascular resistance was calculated as the ratio of pulmonary arterial minus pulmonary wedge pressure to the cardiac output. The systemic vascular resistance was calculated as the ratio of the brachial arterial mean blood pressure to the cardiac output.
The expired gases collected during each period were used to calculate the rates of oxygen uptake and the respiratory exchange ratios. The cardiac output was calculated by the Fick principle for oxygen in all subjects. In 5 of these (MA, CB, RS, JK, and TW), cardiac output and "central blood volume" were also determined by the Stewart-Hamilton principle immediately prior to the end of each period; for this purpose, indocyanine green dye was injected into the pulmonary artery, and brachial arterial blood was withdrawn at a constant rate through a densitometer (Colson) for the inscription of the dye dilution curve by the oscilloscopic recorder (20-22).

The oxygen content and capacity of blood were determined volumetrically, in duplicate, by the method of Van Slyke and Neill (23). The pH of blood was determined using a McInnes-Belcher glass electrode. The oxygen and carbon dioxide content of expired gas were determined in duplicate using a micro-Scholander gas analyzer (24).

The concentrations of epinephrine and norepinephrine in plasma were determined fluorometrically by the trihydroxyindole procedure of Cohen and Goldenberg (25). This method is sensitive to changes of $0.2 \mu \mathrm{g}$ per $\mathrm{L}$ of blood.

Part III. Three other subjects were studied during open thoracotomy. Needles were placed in the pulmonary artery, the left atrium, and the aorta; blood pressures were recorded prior to, during, and after, a single rapid injection of 0.4 or $0.8 \mu \mathrm{g}$ of norepinephrine into the exposed pulmonary artery. Although open thoracotomy undoubtedly produces considerable derangements in the circulation, the simultaneous registration of these blood pressures in the course of a single circulation provides a

TABLE I

Effect of acute hypoxia ${ }^{*}$ on the concentrations of epinephrine and norepinephrine in the systemic arterial blood of normal subjects

\begin{tabular}{|c|c|c|c|c|c|c|c|c|}
\hline \multirow[b]{2}{*}{ Subj. } & \multicolumn{2}{|c|}{$\begin{array}{c}\text { Systemic } \\
\text { arterial } \mathrm{O}_{2} \\
\text { saturation }\end{array}$} & \multicolumn{2}{|c|}{$\begin{array}{c}\text { Pulmonary } \\
\text { arterial mean } \\
\text { pressure }\end{array}$} & \multicolumn{2}{|c|}{ Epinephrine } & \multicolumn{2}{|c|}{ Norepinephrine† } \\
\hline & Air & Hypoxia & Air & Hypoxia & Air & Hypoxia & Air & Hypoxia \\
\hline & \multicolumn{2}{|c|}{$\%$} & \multicolumn{2}{|c|}{$m m \mathrm{Hg}$} & \multicolumn{2}{|c|}{$\mu g / L$} & \multicolumn{2}{|c|}{$\mu g / L$} \\
\hline TM & 100 & 65 & & & 0.19 & 0.20 & 0.24 & 0.28 \\
\hline MD & 99 & 69 & & & 0.17 & 0.23 & 0.23 & 0.16 \\
\hline FT & 96 & 80 & & & 0.04 & 0.07 & 0.24 & 0.22 \\
\hline $\mathrm{AL}$ & 97 & 56 & & & 0.19 & 0.19 & 0.22 & 0.06 \\
\hline $\mathrm{DH}$ & 96 & 70 & & & 0.06 & 0.03 & 0.67 & 0.53 \\
\hline GD & 97 & 77 & & & 0.11 & 0.16 & 0.39 & 0.37 \\
\hline ER & 96 & 68 & & & 0.44 & 0.65 & 0.43 & $0.22^{\circ}$ \\
\hline TN & 98 & 78 & & & 0.44 & 0.15 & 0.46 & 0.49 \\
\hline DG & 96 & 82 & & & 0.18 & 0.44 & 0.09 & 0.06 \\
\hline$\overline{E B}$ & 97 & 68 & 8 & 20 & 0.12 & 0.41 & 0.34 & 0.32 \\
\hline MA & 97 & 71 & 10 & 20 & 0.27 & 0.22 & 0.19 & 0.06 \\
\hline $\mathrm{CU}$ & 99 & 74 & 17 & 26 & 0.23 & 0.22 & 0.21 & 0.21 \\
\hline TA & 99 & 78 & 11 & 17 & 0.20 & 0.12 & 0.30 & 0.10 \\
\hline WT & 97 & 71 & 13 & 21 & 0.25 & 0.17 & 0.20 & 0.12 \\
\hline $\mathrm{CB}$ & 100 & 69 & 20 & 26 & 0.18 & 0.18 & 0.32 & 0.32 \\
\hline $\mathrm{MH}$ & 97 & 81 & 12 & 20 & 0.13 & 0.10 & 0.25 & 0.20 \\
\hline Mean & 98 & 72 & 13 & 21 & 0.20 & 0.22 & 0.30 & 0.23 \\
\hline
\end{tabular}

* Acute hypoxia was induced by the breathing of 11 per cent oxygen in air.

† Concentration in systemic arterial blood. 
measure of sequential changes in resistance. To record these blood pressures, the needles were connected by way of vinyl plastic tubing (26) to the Statham gauges and the electronic recorder.

Part IV. Reserpine (2.5 to $4.0 \mathrm{mg}$ per $\mathrm{kg}$ ) was administered intramuscularly to each of 5 dogs, 18 to 36 hours before they were tested with acute hypoxia. At the time of study, small quantities of pentobarbital (Nembutal) were injected intravenously to induce a state of light anesthesia. Respiration was accomplished by means of an intermittent positive pressure respirator (Bird) connected to the dog by way of an endotracheal tube. As in the human studies, an open circuit was used to deliver either ambient air or a mixture of 11 per cent oxygen in nitrogen, and expired air was collected in a Tissot gasometer. The sequence of the hemodynamic measurements was identical with that described above for periods 1 and 2 of the studies on man.

\section{RESULTS}

1. Measurement of the concentrations of epinephrine and norepinephrine in arterial and mixed venous blood during hypoxia. In the upper portion of Table I are listed the arterial blood concentrations of epinephrine and norepinephrine in 16 normal subjects during ambient air breathing and during hypoxia. Values for the pulmonary arterial mean blood pressures are also indicated for 7 subjects (EB to $M H)$. As may be seen, the arterial oxygen saturation decreased in each subject during hypoxia. During ambient air breathing, the average oxygen saturation for the group was 98 per cent (range, 96 to 100 per cent); during hypoxia, the average saturation fell to 72 per cent. In each of the seven subjects in whom pulmonary arterial pressure was measured, the decrease in systemic arterial oxygen saturation was associated with an increase in pulmonary arterial mean blood pressure; the average increase was 53 per cent. However, despite these changes in peripheral arterial oxygen saturation and in pulmonary arterial pressure during hypoxia, there was no statistically significant change $(p>0.1)$ in the concentration either of epinephrine or of norepinephrine in the peripheral arterial blood.

The relationship between the concentrations of catecholamines in arterial blood and in mixed venous blood drawn simultaneously is shown for five subjects in Table II. The test periods when the comparisons were made are indicated in the second column. It may be seen that there was no arteriovenous difference for norepinephrine greater
TABLE II

Concentrations of norepinephrine and epinephrine in blood withdrawn simultaneously from the pulmonary and brachial arteries *

\begin{tabular}{|c|c|c|c|c|c|}
\hline \multirow[b]{2}{*}{ Subject } & \multirow[b]{2}{*}{ Test period } & \multicolumn{2}{|c|}{ Norepinephrine } & \multicolumn{2}{|c|}{ Epinephrine } \\
\hline & & PA & BA & PA & BA \\
\hline & & \multicolumn{2}{|c|}{$\mu g / L$} & \multicolumn{2}{|c|}{$\mu g / L$} \\
\hline CB & Hypoxia & 0.32 & 0.36 & 0.39 & 0.41 \\
\hline TA & Hypoxia + NE & 1.50 & 1.71 & 0.31 & 0.28 \\
\hline EC & $\mathrm{NE}$ & 1.34 & 1.26 & 0.16 & 0.19 \\
\hline EB & NE & 4.13 & 4.35 & 0.24 & 0.22 \\
\hline MH & NE & 5.35 & 5.24 & 0.29 & 0.61 \\
\hline
\end{tabular}

${ }^{*} \mathrm{PA}=$ pulmonary artery; $\mathrm{BA}=$ brachial artery; $\mathrm{NE}$ $=$ norepinephrine infusion.

than $0.2 \mu \mathrm{g}$ per $\mathrm{L}$ in any of the subjects. In only one of the five subjects $(\mathrm{MH})$ was the arteriovenous difference for epinephrine greater than 0.2 $\mu \mathrm{g}$ per $\mathrm{L}(0.32 \mu \mathrm{g}$ per $\mathrm{L})$.

2. Duplication of the pulmonary arterial hypertension observed during hypoxia by the infusion of norepinephrine. The rates at which norepinephrine had to be infused during ambient air breathing in order to duplicate the level of pulmonary arterial pressure which occurred during acute hypoxia are listed for each subject in Table III (period 3). It may be seen that the rates varied from subject to subject, and ranged from 12 to $67 \mu \mathrm{g}$ per minute $(0.17$ to $1.4 \mu \mathrm{g}$ per minute per $\mathrm{kg}$ ). In 8 of the 13 subjects, peripheral arterial blood samples were drawn after a stable level of pulmonary hypertension had persisted for 8 to 10 minutes. As shown in Table III, the concentrations of norepinephrine in these samples ranged from 1.6 to $5.8 \mu \mathrm{g}$ per L. These levels of circulating norepinephrine, which were required to duplicate the hypoxic increase in pulmonary arterial pressure, were from 13 to 22 times higher than the levels of norepinephrine which occurred spontaneously in the same subjects during acute hypoxia (period 2).

3. Comparison of the ventilatory and circulatory effects of acute hypoxia and of norepinephrine in the same subjects. Table III also lists the ventilatory and circulatory measurements obtained from each subject during the four consecutive test periods. In this section, only the measurements of the first three test periods (e.g. control, hypoxia, and infusion of norepinephrine) will be compared; for convenience, the final period will be considered separately. 


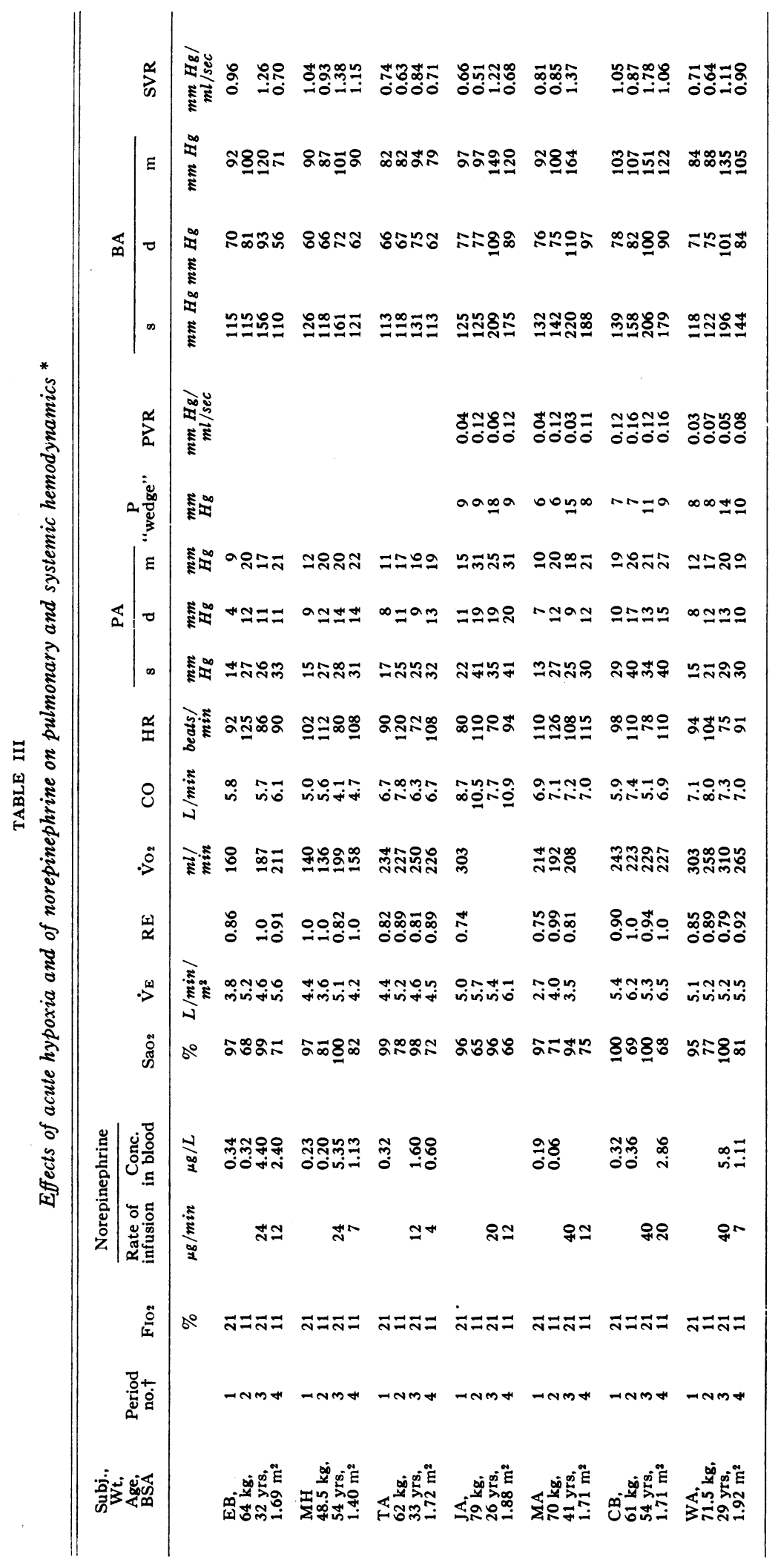


CATECHOLAMINES DURING ACUTE HYPOXIA

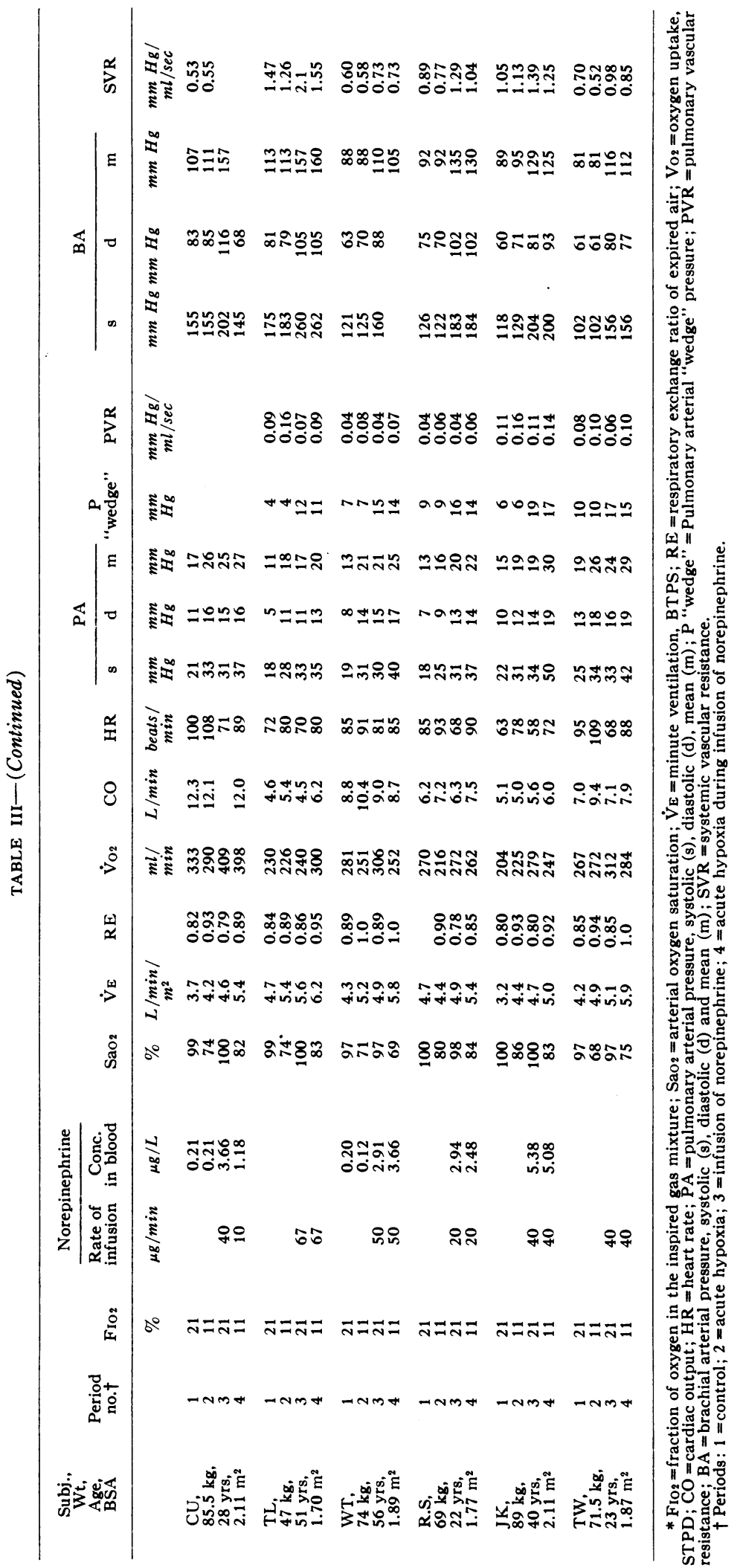




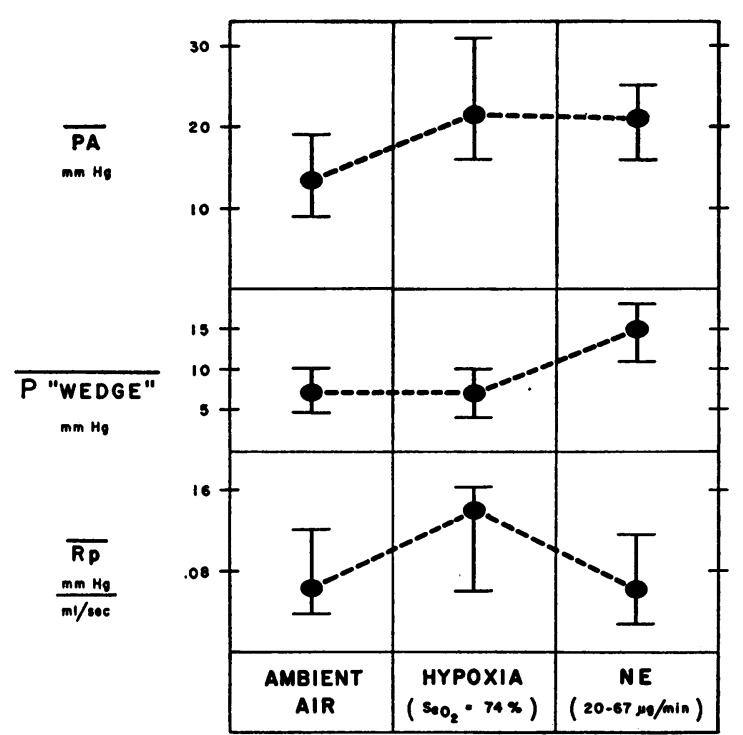

Fig. 1. CoMparison OF THE EFFECTS OF ACUTE HyPOXIA AND OF THE INFUSION OF NOREPINEPHRINE ON PULMONARY VASCULAR PRESSURES AND RESISTANCE. PA $=$ mean pulmonary arterial pressure; $\overline{\mathrm{P}}$ "wedge" $=$ mean pulmonary arterial wedge pressure; $\overline{\mathrm{Rp}}=$ mean pulmonary vascular resistance. The solid circles represent average values for the group; the bars represent the range.

During the control period, the minute ventilation averaged $4.3 \mathrm{~L}$ per minute per $\mathrm{m}^{2}$ of body surface area, and increased by approximately 10 per cent during hypoxia and norepinephrine infusion, respectively. The respiratory exchange ratios were 1.0 or less throughout each of the periods. In all subjects but one (MA), the respiratory exchange ratio during the hypoxic period differed from control by 0.13 or less. In Subject MA, the inordinate increase of 0.24 in the respiratory exchange ratio, as well as the 10 per cent decrease in oxygen uptake, raised the prospect that his value for cardiac output during hypoxia might be artificially low (3). However, independent determinations of the cardiac output by the Stewart-Hamilton dye dilution method in Subject MA and in four others ( $\mathrm{CB}, \mathrm{RS}, \mathrm{JK}$, and TW) during each of the three periods provided values which did not differ from the corresponding Fick values by more than 12 per cent. Because of this close agreement, the values obtained by the dye dilution method are not included in the table.

The average cardiac output by the Fick method during the control period was $6.8 \mathrm{~L}$ per minute. In Subject CU, the control cardiac output was un- usually high $\left(5.8 \mathrm{~L}\right.$ per minute per $\mathrm{m}^{2}$ of body surface area); this high level persisted, without apparent reason, throughout the test periods. During hypoxia, cardiac output increased in 9 of the 13 subjects, with an average increase for the group of 19 per cent. During the infusion of norepinephrine, the average cardiac output was 7 per cent less than control.

During hypoxia, the heart rate increased in each subject, averaging 15 beats more per minute than during the control period. The corresponding changes in stroke volume were slight and inconsistent in direction $(-17$ to $+12 \mathrm{ml})$. During the infusion of norepinephrine, the heart rate decreased in 10 of the 13 subjects, averaging approximately 15 beats less per minute than during the control period. The stroke volumes either remained unchanged or increased: in 8 of the 13 subjects, the increments in stroke volume were 5 $\mathrm{ml}$ or less; in the other 5 , the increments ranged from 8 to $30 \mathrm{ml}$.

The changes in pulmonary arterial and wedge pressures, and in pulmonary vascular resistance are presented in detail in Table III and summarized for each of the three periods in Figure 1. The figure illustrates that, according to plan, approximately equal levels of pulmonary arterial pressure were achieved during periods 2 (hypoxia) and 3 (norepinephrine). However, these two periods are strikingly different with respect to both the pulmonary wedge pressures and calculated resistance. In contrast to the unchanged wedge pressure and the increased resistance during hypoxia, the wedge pressure increased (by 4 to $13 \mathrm{~mm} \mathrm{Hg}$ ) and the resistance remained unchanged during the infusion of norepinephrine: on the average, the pulmonary vascular resistance rose from $0.06 \pm 0.02 \mathrm{~mm} \mathrm{Hg}$ per $\mathrm{ml}$ per second during ambient air breathing to $0.14 \pm 0.04 \mathrm{~mm}$ $\mathrm{Hg}$ per $\mathrm{ml}$ per second during hypoxia; it reverted to control values $(0.06 \pm 0.03 \mathrm{~mm} \mathrm{Hg}$ per $\mathrm{ml}$ per second) during the infusion of norepinephrine.

Several other observations not listed in Table III are relevant to the interpretation of these data : 1) continuous records of pulmonary vascular pressures during the infusion of norepinephrine showed that the increase in pulmonary arterial pressure either accompanied or followed the increase in wedge pressure but never preceded it; 2) in the 
four subjects in whom measurements of right ventricular end-diastolic pressures were obtained during all three periods (EB, $\mathrm{MH}, \mathrm{TA}$, and $\mathrm{CU})$, these pressures were found to remain unchanged during hypoxia (of the order of 1 to $2 \mathrm{~mm} \mathrm{Hg}$ ) and to increase during the infusion of norepinephrine (the highest value for end-diastolic pressure, $8 \mathrm{~mm} \mathrm{Hg}$, occurred in Subject CU, who received the most rapid infusion of norepinephrine); and 3 ) in the five subjects in whom the central blood volume was measured (MA, $\mathrm{CB}, \mathrm{RS}, \mathrm{JK}$, and TW), the values during hypoxia and during the infusion of norepinephrine did not vary significantly ( \pm 15 per cent) from control.

The effects of hypoxia and of norepinephrine on the systemic circulation appear in the final columns of Table III. During hypoxia, the systemic arterial pressure and the systemic vascular resistance remained unchanged despite the increase in pulmonary vascular resistance. On the other hand, during the infusion of norepinephrine, the systemic arterial pressure and systemic vascular resistance increased even though the pulmonary vascular resistance remained unchanged.

4. The effect of the combination of acute hypoxia and the infusion of norepinephrine on the pulmonary circulation. The respiratory and circulatory responses of each subject to acute hypoxia during the infusion of norepinephrine (period 4) are listed in Table III for comparison with the responses during acute hypoxia per se (period 2). The subjects are divided into two groups according to the rates of infusion: a slow rate of infusion (4 to $20 \mu \mathrm{g}$ per minute) increased the level of circulating norepinephrine without increasing pulmonary arterial pressure (Subjects EB to CU); a more rapid rate (20 to $67 \mu \mathrm{g}$ per minute) increased the pulmonary arterial pressure to the levels of period 3 (Subjects TL to TW). Despite these variations in the rate of infusion, the levels of the minute ventilation, respiratory exchange ratios, and peripheral arterial oxygenation of period 4 were similar to those of period 2.

In Figure 2, the pulmonary vascular pressure and resistance during periods 2 and 4 are com-

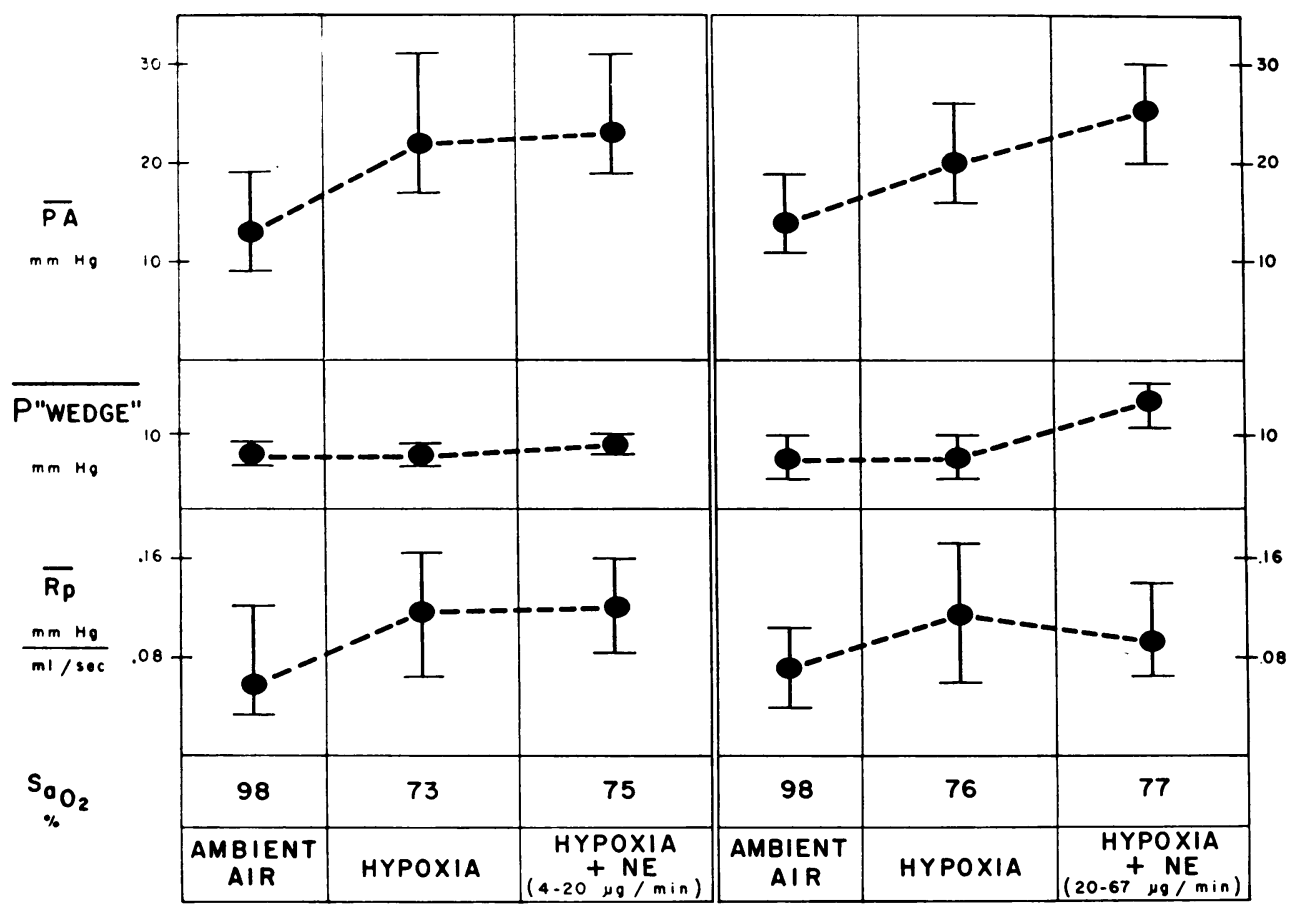

Fig. 2. COMPARISON OF THE EFFeCtS OF A SLOW INFUSION OF NOREPINEPHRINE (4 To $20 \mu \mathrm{G}$ PER MINUTE) AND OF A RAPID INFUSION (20 TO $67 \mu \mathrm{G}$ PER MINUTE) ON THE PULMONARY ARTERIAL PRESSOR RESPONSE TO ACUTE HYPOXIA. The solid circles represent average values; the bars represent the range. For each period, the average peripheral arterial oxygen saturation is also indicated. 


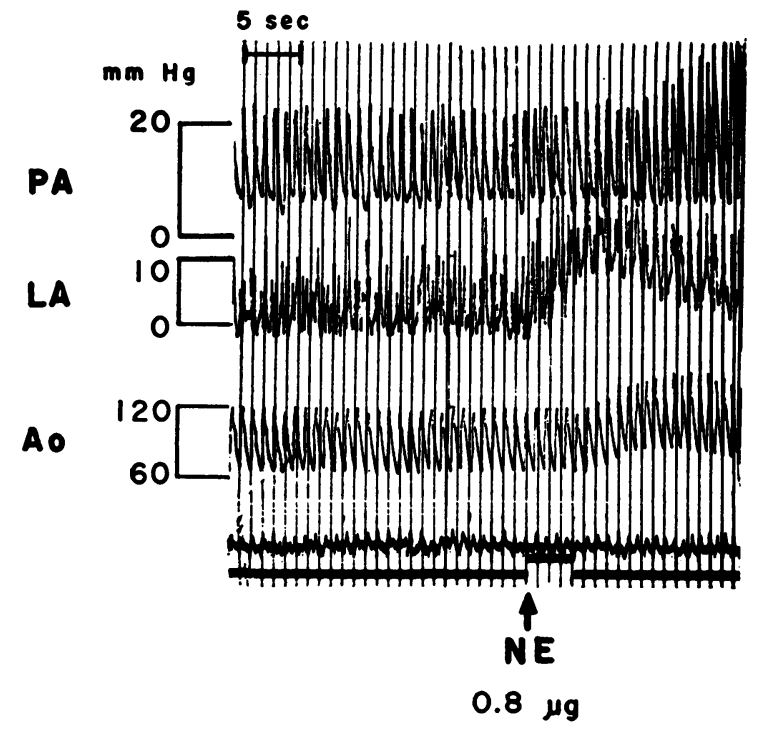

Fig. 3. Simultaneous blood pressures Recorded FROM THE PULMONARY ARTERY (PA), LEFT ATRIUM (LA) AND AORTA (Ao) DURING OPEN THORACOTOMY. At arrow, $0.8 \mu \mathrm{g}$ of norepinephrine (NE) was injected rapidly into the main pulmonary artery.

pared. The left half of this figure is concerned with the effects of the slow infusion rates (4 to 20 $\mu \mathrm{g}$ per minute), and the right half with the effects of the rapid infusion rates (20 to $67 \mu \mathrm{g}$ per minute). It may be seen that the slow infusion of norepinephrine did not modify the pulmonary vascular response to acute hypoxia. On the other hand, during the rapid infusion of norepinephrine, the increase in pulmonary arterial pressure exceeded that which occurred during acute hypoxia per se. However, because of the concomitant increase in pulmonary wedge pressure, the value for pulmonary vascular resistance did not exceed that which obtained during acute hypoxia per se.

5. The effect of a single injection of norepinephrine directly into the pulmonary artery in openchested subjects. Figure 3 illustrates the sequence of changes in blood pressure recorded simultaneously from the pulmonary artery, the left atrium, and the aorta, before and after an injection of norepinephrine directly into the exposed pulmonary artery of a human subject during thoracotomy. It may be seen that the first increase in pressure occurred in the left atrium 2.5 seconds after the injection; this was followed by an increase in aortic pressure 6 seconds after the injection.
The pulmonary arterial pressure was the last to increase, 11 seconds after injection.

6. The effect of depleting the lungs of norepinephrine on the pulmonary pressor response to hypoxia in dogs. Figure 4 compares the changes in the cardiac output and pulmonary arterial mean pressure of five reserpinized dogs during acute hypoxia with the changes observed in four other nonreserpinized dogs previously studied in this laboratory in the same way (27). It may be seen that the pulmonary arterial pressor response observed during hypoxia in the reserpinized dogs was the same as the response of the control dogs.

\section{DISCUSSION}

The results of these observations on man indicate that circulating epinephrine and norepinephrine are not involved in the pulmonary arterial pressor response to acute hypoxia of moderate degree. This conclusion is based on several lines of evidence: 1) the concentrations of these catecholamines in blood during acute hypoxia do not exceed the concentrations during ambient air breathing; 2) the levels of circulating norepinephrine which must be reached during ambient air breathing in order to duplicate the pulmonary hypertension of acute hypoxia are far in excess of those which occur spontaneously during acute hypoxia; 3) circulating norepinephrine seems to elicit pulmonary hypertension by a different mechanism from that which operates during acute hypoxia; and 4) an increase in the level of the circulating norepinephrine that is insufficient to raise the pulmonary wedge pressure does not augment the pulmonary arterial pressor response to acute hypoxia.

These observations on the circulating catecholamines do not exclude the possibility that the release of norepinephrine at intrapulmonary vascular nerve endings may be involved (28). However, the present study also suggests that this prospect is unlikely, since the administration of reserpine to dogs, in doses larger than those conventionally used to deplete canine tissues of norepinephrine (29), did not prevent or blunt the rise in pulmonary arterial pressure during acute hypoxia. This failure of reserpine to modify the pulmonary arterial pressor response is consistent with the persistence of this response in man in the face of 
surgical sympathectomy $(30,31)$ and "chemical" denervation (32).

It is generally agreed that acute hypoxia elicits pulmonary hypertension by inducing pulmonary vasoconstriction $(3,33)$. There is less unanimity concerning the mechanism by which the infusion of norepinephrine elevates pulmonary arterial pressure: on the one hand there is evidence that "back pressure" from the left heart is involved (34-37); on the other there is evidence that pulmonary vascular resistance increases $(35,38-41)$. The present study indicates that in intact man the "back pressure" effect predominates. The evidence for this view is of several different types: 1) after the injection of norepinephrine into the exposed pulmonary artery during open thoracotomy, the increase in left atrial and aortic pressures preceded the increase in pulmonary arterial pressure; 2) during the infusion of norepinephrine, the increase in pulmonary arterial pressure either accompanied or followed the increase in pulmonary wedge pressure but never preceded it; and 3 ) the infusion of norepinephrine during acute hypoxia (i.e., when pulmonary vasoconstriction presumably exists) failed to elicit any further increase in pulmonary vascular resistance.

These studies do not indicate the precise mechanisms by which norepinephrine increases the pulmonary wedge pressure. In particular, the failure of norepinephrine to decrease consistently the calculated pulmonary vascular resistance (42) raises the prospect that norepinephrine elicits a combination of pulmonary vasoconstriction and "back pressure." However, the sequence of changes in left atrial and aortic pressures after the injection of norepinephrine into the pulmonary artery suggests that a direct effect of norepinephrine on left atrial muscle is primarily involved. This hypothesis is consistent with the positive inotropic effect of norepinephrine on isolated cardiac muscle (43).

\section{SUMMARY}

1. The role of circulating catecholamines in the pulmonary arterial pressor response to acute hypoxia of moderate degree was investigated in 25 human subjects. Supplementary observations on five dogs concerned the role of norepinephrine contained in pulmonary nerve endings.

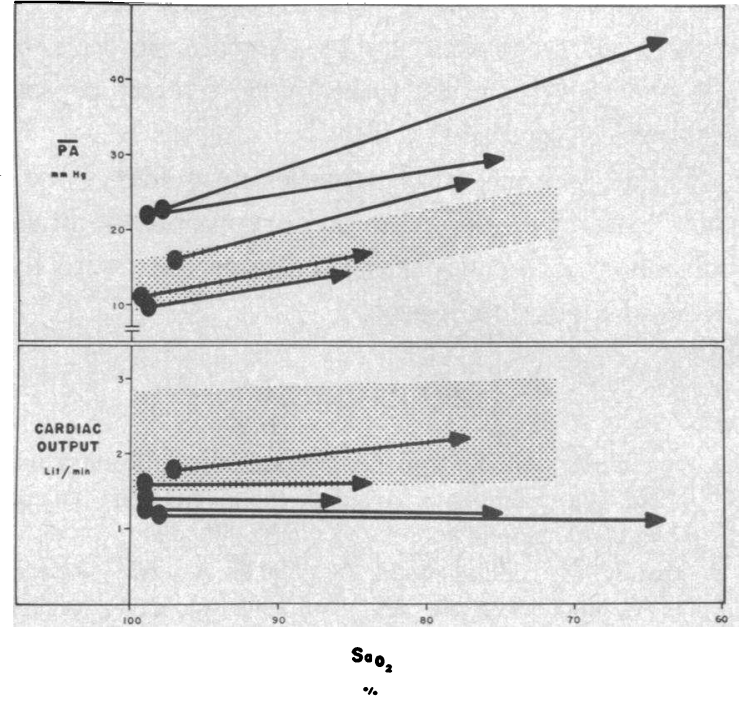

Fig. 4. EFFect of ACUTE hypoxia (11 PER CENT OXYGEN IN NITROGEN) ON THE PULMONARY ARTERIAL MEAN PRESSURE ( $\overline{\mathrm{PA}}$ ) AND THE CARDIAC OUTPUT IN FIVE DOGS PRETREATED WITH LARGE DOSES OF RESERPINE. In both the upper and lower frames the stippled areas represent the control values based on four nonreserpinized dogs exposed to the same degree of acute hypoxia and studied under similar circumstances in this laboratory (27). Each solid circle represents the control value of a reserpinized dog during ambient air breathing; the arrowhead represents the value obtained in the same animal during acute hypoxia.

2. Acute hypoxia was not associated with an increase in the levels of circulating epinephrine or norepinephrine.

3. During ambient air breathing, the levels of circulating norepinephrine had to be increased at least 13 times above control levels in order to duplicate the pulmonary arterial pressor response to acute hypoxia.

4. In intact man the infusion of norepinephrine elicited pulmonary arterial hypertension by a mechanism different from that of acute hypoxia: the pressor response to acute hypoxia arose from an increased pulmonary vascular resistance to perfusion; the pressor response to norepinephrine originated primarily in "back pressure" from the left heart (i.e., without an increase in pulmonary vascular resistance).

5. Levels of circulating norepinephrine that were insufficient to increase the pulmonary wedge pressure did not exaggerate the pulmonary arterial pressor response to acute hypoxia. 
6. Depletion of the pulmonary vascular nerve endings of norepinephrine by reserpine in dogs did not prevent the usual pulmonary arterial pressor response to acute hypoxia.

7. The present study provides no evidence for a role of either epinephrine or norepinephrine in the pulmonary arterial pressor response to acute hypoxia of moderate degree.

\section{REFERENCES}

1. von Euler, U. S., and Liljestrand, G. Observations on the pulmonary arterial blood pressure in the cat. Acta physiol. scand. 1946, 12, 301.

2. Motley, H. L., Cournand, A., Werko, L., Himmelstein, A., and Dresdale, D. Influence of short periods of induced acute hypoxia upon pulmonary artery pressures in man. Amer. J. Physiol. 1947, 150, 315.

3. Westcott, R. N., Fowler, N. O., Scott, R. C., Hauenstein, V. D., and McGuire, J. Anoxia and human pulmonary vascular resistance. J. clin. Invest. 1951, 30, 957.

4. Fishman, A. P., McClement, J., Himmelstein, A., and Cournand, A. Effects of acute anoxia on the circulation and respiration in patients with chronic pulmonary disease studied during the "steady state." J. clin. Invest. 1952, 31, 770.

5. Stroud, R. C., and Rahn, H. Effect of $\mathrm{O}_{2}$ and $\mathrm{CO}_{2}$ tensions upon the resistance of pulmonary blood vessels. Amer. J. Physiol. 153, 172, 211.

6. Hürlimann, A., and Wiggers, C. J. Effects of progressive general anoxia on the pulmonary circulation. Circulat. Res. 1953, 1, 230.

7. Aviado, D. M., Jr., Cerletti, A., Alanis, J., Bulle, P. H., and Schmidt, C. F. Effects of anoxia on pressure, resistance and blood volume $\left(\mathrm{P}^{32}\right)$ of pulmonary vessels. Amer. J. Physiol. 1952, 169, 460.

8. Bülbring, E., Burn, J. H., and De Elio, F. J. The secretion of adrenaline from the perfused suprarenal gland. J. Physiol. (Lond.) 1948, 107, 222.

9. Cannon, W. B., and Hoskins, R. G. The effects of asphyxia, hyperpnea, and sensory stimulation on adrenal secretion. Amer. J. Physiol. 1911, 29, 274.

10. Houssay, B. A., and Molinelli, E. A. Adrenal secretion produced by asphyxia. Amer. J. Physiol. $1926,76,538$.

11. Van Middlesworth, L., Kline, R. F., and Bretton, S. W. Carbohydrate regulation under severe anoxic conditions. Amer. J. Physiol. 1943, 140, 474.

12. Van Loo, A., Surtshin, A., and Katz, L. N. Nature of the two pressor responses to acute hypoxemia with some observations on the role of the adrenals in hypoxia. Amer. J. Physiol. 1948, 154, 397.
13. Emerson, G. A., and Van Liere, E. J. Adrenin content of adrenals of cats subjected to anoxia. Proc. Soc. exp. Biol. (N. Y.) 1938, 38, 500.

14. McQuarrie, I., Ziegler, M. R., Stone, W. E., Wangensteen, O. H., and Dennis, C. Mechanism of insulin convulsions. III. Effects of varying partial pressures of atmospheric gases after adrenalectomy. Proc. Soc. exp. Biol. (N. Y.) 1939, 42, 513.

15. Feldman, J., Cortell, R., and Gellhorn, E. On the vago-insulin and sympathetico-adrenal systems and their mutual relationship under conditions of central excitement induced by anoxia and convulsant drugs. Amer. J. Physiol. 1940, 131, 281.

16. Redgate, E. S., and Gellhorn, E. Nature of sympathetico-adrenal discharge under conditions of excitation of central autonomic structures. Amer. J. Physiol. 1953, 174, 475.

17. Ludemann, H., Filbert, M. G., and Cornblath, M. Application of a fluorimetric method for adrenalinelike substances in peripheral plasma. J. appl. Physiol. 1955, 8, 59..

18. Cohen, G., Holland, B., Sha, J., and Goldenberg, M. Plasma concentrations of epinephrine and norepinephrine during intravenous infusions in man. J. clin. Invest. 1959, 38, 1935.

19. Hellems, H. R., Haynes, F. W., and Dexter, L. Pulmonary "capillary" pressure in man. J. appl. Physiol. 1949, 2, 24.

20. Hamilton, W. F., Moore, J. W., Kinsman, J. M., and Spurling, R. G. Studies on the circulation. IV. Further analysis of the injection method, and of changes in hemodynamics under physiological and pathological conditions. Amer. J. Physiol. 1932, 99, 534.

21. Shadle, O. W., Ferguson, T. B., Gregg, D. E., and Gilford, S. R. Evaluation of a new cuvette densitometer for determination of cardiac output. Circulat. Res. 1953, 1, 200.

22. Fox, I. J., Brooker, L. G., Heseltine, D. W., Essex, H. E., and Wood, E. H. A tricarbocyanine dye for continuous recording of dilution curves in whole blood independent of variations in blood oxygen saturation. Proc. Mayo Clin. 1957, 32, 478.

23. Van Slyke, D. D., and Neill, J. M. The determination of gases in blood and other solutions by vacuum extraction and manometric measurement. I. J. biol. Chem. 1924, 61, 523.

24. Scholander, P. F. Analyzer for accurate estimation of respiratory gases in one-half cubic centimeter samples. J. biol. Chem. 1947, 167, 235.

25. Cohen, G., and Goldenberg, M. The simultaneous fluorimetric determination of adrenaline and noradrenaline in plasma. I. The fluorescence characteristics of adrenolutine and noradrenolutine and their simultaneous determination in mixtures. J. Neurochem. 1957, 2, 58.

26. Braunwald, E., Moscovitz, H. L., Amram, S. S., Lasser, R. P., Sapin, S. O., Himmelstein, A., 
Ravitch M., and Gordon, A. J. The hemodynamics of the left side of the heart as studied by simultaneous left atrial, left ventricular, and aortic pressures; particular reference to mitral stenosis. Circulation 1955, 12, 69.

27. Bergofsky, E., Lehr, D. E., Tuller, M. A., Rigatto, M., and Fishman, A. P. The effects of acute alkalosis and acidosis on the pulmonary circulation. Ann. N. Y. Acad. Sci. 1961, 92, 626.

28. Folkow, B. Nervous control of the blood vessels. Physiol. Rev. 1955, 35, 629.

29. Burn, J. H., and Rand, M. J. Noradrenaline in artery walls and its dispersal by reserpine. Brit. med. J. 1958, 1, 903.

30. Fishman, A. P. Respiratory gases in the regulation of the pulmonary circulation. Physiol. Rev. $1961,4,214$.

31. Fritts, H. W., Jr., Harris, P., Clauss, R. H., Odell, J. E., and Cournand, A. The effect of acetylcholine on the human pulmonary circulation under normal and hypoxic conditions. J. clin. Invest. 1958, 37, 99.

32. Bishop, J. M., Harris, P., and Segel, N. The influence of guanethidine on the response of the human pulmonary circulation to hypoxia. J. Physiol. (Lond.) 1961, 156, 40P.

33. Doyle, J. T., Wilson, J. S., and Warren, J. V. The pulmonary vascular response to short-term hym poxia in human subjects. Circulation 1952, 5, 263.

34. Fowler, N. O., Westcott, R. N., Scott, R. C., and McGuire, J. The effect of nor-epinephrine upon pulmonary arteriolar resistance in man. J. clin. Invest. 1951, 30, 517.

35. Regan, T. J., Defazio, V., Binak, K., and Hellems, H. K. Norepinephrine induced pulmonary congestion in patients with aortic valve regurgitation. J. clin. Invest. 1959, 38, 1564.
36. Johnson, V., Hamilton, W. F., Katz, L. N., and Weinstein, W. Studies on the dynamics of the pulmonary circulation. Amer. J. Physiol. 1937, $120,624$.

37. Hamilton, W. F., Woodbury, R. A., and Vogt, E. Differential pressures in the lesser circulation of the unanesthetized dog. Amer. J. Physiol. 1939, 125, 130.

38. Patel, D. J., Lange, R. L., and Hecht, H. H. Some evidence for active constriction in the human pulmonary vascular bed. Circulation 1958, 18, 19.

39. Rose, J. C., Freis, E. D., Hufnagel, C. A., and Massullo, E. A. Effects of epinephrine and nor-epinephrine in dogs studied with a mechanical left ventricle. Demonstration of active vasoconstriction in the lesser circulation. Amer. J. Physiol. 1955, 182, 197.

40. Daly, M. de B., and Luck, C. P. The effects of adrenaline and noradrenaline on pulmonary haemodynamics with special reference to the role of reflexes from carotid sinus baroreceptors. J. Physiol. (Lond.) 1959, 145, 108.

41. Borst, H. G., Berglund, E., and McGregor, M. The effects of pharmacologic agents on the pulmonary circulation in the dog. Studies on epinephrine, nor-epinephrine, 5-hydroxytryptamine, acetylcholine, histamine and aminophylline. J. clin. Invest. 1957, 36, 669.

42. Borst, H. G., McGregor, M., Whittenberger, J. L., and Berglund, $\mathrm{E}$. Influence of pulmonary arterial and left atrial pressures on pulmonary vascular resistance. Circulat. Res. 1956, 4, 393.

43. Goldberg, L. I., Cotten, M. de V., Darby, T. D., and Howell, E. V. Comparative heart contractile force effects of equipressor doses of several sympathomimetic amines. J. Pharmacol. exp. Ther. 1953, 108, 177. 